\title{
Cultura hip-hop e enfrentamento à violência: uma estratégia universitária extensionista
}

\author{
Jaquelina Maria Imbrizi, (D) * Eduardo de Carvalho Martins, (D) Marcela Garrido Reghin, \\ Danielle Kepe de Souza Pinto, (D) Daniel Péricles Arruda (D) \\ Universidade Federal de São Paulo, São Paulo, SP, Brasil
}

\section{Resumo}

Os projetos de extensão e pesquisa das universidades precisam se haver com o racismo manifesto nas relações entre pessoas e nos dados estatísticos sobre morte dos brasileiros. O mapa da violência de 2016 explicitou mais uma vez o extermínio de jovens negros do sexo masculino. Como o luto é elaborado pelos familiares e quais as condições que freariam a violência? O objetivo do artigo é apresentar o projeto de extensão "Escuta Clínico-Política de Sujeitos em Situações Sociais Críticas", que nasceu com o intuito de ouvir mães que perderam filhos em situações de violência de Estado e oferecer atividades para adolescentes e jovens em luta pela vida. Um dos métodos utilizados nas ações extensionistas foi a oferta de uma roda de conversa, "Hip-hop e o enfrentamento à Violência", cujo resultado foi a emergência de três temas: cultura hip-hop como um sonho possível; manifestação cultural como ponto de ancoragem para os sujeitos; e arte como modo de ocupação dos espaços públicos. Assim, os autores convidam os psicólogos a criarem espaços de fala, escuta e ação que resistam ao racismo, à violação de direitos e problematizem as condições que geram a desigualdade social brasileira.

Palavras-chave: violência; hip-hop; escuta; clínico-politica; juventudes.

\section{Hip-hop culture and the fight against violence: an extensionist university strategy}

\begin{abstract}
The extension and research college projects need deal with the racism manifest in the relations between people and in the statistical data about young Brazilians deaths. The map of the violence of 2016 made explicit the extermination of young black males. How is mourning drawn up by family members and what conditions would restrain violence? The purpose of this article is to present the project "Clinical-political hearing of subjects in critical social situations" that was born with the intention of listening to mothers who lost children in situations of State violence, as well as with the objective of offering activities for adolescents and young people struggling for life. One of the methods used in the extensionist actions was the offer of a conversation wheel, "Hip-hop and the Fight against Violence", whose result was the emergence of three themes; hip-hop culture as a possible dream; cultural manifestation as an anchorage point for the subjects; art as a way of occupying public spaces. Therefore, the authors invite the psychologists to create spaces of hearing, talking and action about brazilian social inequality.
\end{abstract}

Keywords: violence; hip-hop; hearing; clinical-political; youths.

\section{Introdução}

O ensino superior brasileiro está tendo que se haver, cada vez mais, com o racismo institucional manifesto nas relações entre as pessoas que convivem no ambiente universitário. Isto se deve, em parte, ao novo perfil socioeconômico e cultural de estudantes que conquistaram o acesso ao ensino público e gratuito por meio das políticas afirmativas do governo Lula (2003-2010), responsáveis pela criação e expansão do número de universidades públicas federais no Brasil, a partir de 2005, e pela posterior implantação da Lei de Cotas para vestibulares em 2012 (BRASIL, 2012). Dados estatísticos mostram que há “"[...] um aumento no número de estudantes negros (pretos e pardos), de famílias de baixa renda e um leve aumento na idade média dos graduandos" (RODRIGUES, 2016). Assim, há um paulatino espelhamento no ambiente universitário das características da população brasileira, composta em mais de $50 \%$ por negros.

\footnotetext{
^Endereço para correspondência: Universidade Federal de São Paulo, Campus Baixada Santista, Público. Rua Silva Jardim - lado par - Vila Matias, Santos, SP - Brasil. CEP. 11015020. E-mails: jaque imbrizi@gmail.com, dupsimart@ yahoo.com.br, marcelagarrido.r@hotmail.com, danny kepe@hotmail.com.

Os dados completos dos autores encontram-se ao final do artigo.
}

Outra imagem especular nacional mais próxima de um mal-estar contemporâneo se refere ao fato de que há também na sociedade brasileira um visível racismo estrutural, evidenciado pelos dados alarmantes do último Mapa da Violência no Brasil (WAISELFSZ, 2016). Ao contrário do que se possa imaginar em um primeiro momento, este mapa explicitou não uma "guerra civil" generalizada, mas, sobretudo, um tipo de extermínio muito bem direcionado contra um perfil econômico, etário e étnico-racial específico e delimitado: "De cada 100 pessoas que sofrem homicídio no Brasil, 71 são negras. Jovens e negros do sexo masculino continuam sendo assassinados todos os anos como se vivessem em situação de guerra" (CERQUEIRA et al., 2017, p. 30).

Machado (2017, p. 22) também enfatiza que os jovens são tanto vítimas de homicídios e de causas externas envolvendo circunstâncias violentas, como também são os que cometem algum tipo de delito relacionado às condições de desigualdade social nas cidades. Portanto, a pesquisadora indica o número elevado de adolescentes e jovens que estão "[...] cumprindo medida socioeducativa 
em situação de internação ou semiliberdade na Fundação Casa, algo em torno de 9 mil, sendo $42 \%$ por tráfico de drogas somente no Estado de São Paulo".

Na região da Baixada Santista, onde se localiza um dos campi de expansão da Universidade Federal de São Paulo, podemos citar a especificidade de acontecimentos violentos que desembocaram na morte de jovens, no mês de maio de 2006, em decorrência de confrontos envolvendo o Primeiro Comando da Capital (PCC) e as polícias militar e civil. Nesse período, 505 civis e 59 agentes públicos foram assassinados no Estado de São Paulo (CRUZ, 2016). As mães desses jovens mortos em decorrência de situações de violência criaram o "Movimento Mães de Maio", que reúne familiares das vítimas de violência do Estado e se dedica a denunciar constantes violações de direitos humanos.

A Universidade Pública, nesse contexto, pode exercer um papel ativo diante deste racismo institucional e estrutural que tem consequências nefastas para todo o conjunto da sociedade. Uma de suas funções seria a de produzir conhecimento e desenvolver tecnologias sociais para desconstruir este cenário de barbárie que acomete nossas cidades. Diante desse desafio, um grupo de estudantes, professores e psicólogos criou o Projeto de Extensão Universitária Escuta clínico-política de sujeitos em situações sociais críticas (IMBRIZI; MARTINS, 2017). Este projeto visa transmitir conhecimentos e, sobretudo, produzir intervenções que façam face às questões pungentes da sociedade contemporânea: a violência, o sofrimento sociopolítico, e, quiçá, a superação da progressiva superação das condições sociais e históricas que reproduzem a dominação e a segregação social presentes em nossa sociedade.

Uma das diretrizes do projeto consiste na criação de dispositivos que atuem no sentido de manter estes jovens vivos, para que continuem "tocando a vida em frente" e encontrem razões e sonhos que suscitem o desejo de viver. O desafio, então, é desenvolver aparatos de circulação da palavra por meio da oferta de escuta, como rodas de conversa e oficinas, em suas articulações com as manifestações culturais e artísticas.

O objetivo deste artigo é mapear e apresentar a experiência da roda de conversa intitulada "Hip-hop e o enfrentamento à violência". Para tanto, contextualizamos a cultura hip-hop, apresentamos como operou a roda de conversa e, por fim, discutimos temas que emergiram no encontro.

\section{Contextualização e construção histórico-social da cultura hip-hop}

Segundo Arruda (2017), a cultura hip-hop tem por base as raízes africanas e jamaicanas, se desenvolvendo nos Estados Unidos e chegando ao Brasil na década de 1980. O autor faz referências aos griots, trovadores guardiões da história cultural que ensinavam arte, imersos no folclore de canções faladas.

Fractal, Rev. Psicol., v. 31 - n. esp., p. 166-172, set. 2019
Há que se ressaltar que na Jamaica, em 1960, surgiram os sound systems, consistindo em grupos formados por jovens que organizavam festas e manifestações culturais e que já denunciavam as condições políticas e econômicas do país em que viviam.

Da cultura caribenha é possível citar o toast, modo rítmico muito próximo de um cantar falado e que, entre as décadas de 70 e 80, por intermédio do grupo americano Sugar Hill Gang, influenciou muitos jovens americanos.

Talvez a característica sociocultural do contexto americano, na década de 1970, tenha favorecido a intrínseca relação entre música, dança e as lutas pela conquista dos direitos civis da população negra. Arruda (2017) assinala a importância do movimento black power na década de 1970, no qual a arte e, em especial, a música, consistia em uma forma de protesto, fazendo parte do caminho para a manifestação e, também, um modo de enfrentar a violência da sociedade e do Estado. É neste solo híbrido e multicultural que estão dadas as condições para a emergência do Rap (Rhythm And Poetry / ritmo e poesia). Também são manifestações culturais da juventude americana o hip (saltar/pular) e o hop (movimentando os quadris), e que, mais tarde, foram utilizados para nomear a cultura hip-hop.

Outro importante artista, Afrika Bambaataa, nasceu em 1957 em Nova Iorque e organizou muitos eventos com o objetivo de unir os cinco elementos desta cultura: o DJ, o MC, o breaking, o graffitti e o conhecimento sobre as raízes históricas da segregação cultural e física do povo negro. O DJ é responsável pela batida marcante do rap e utiliza vários instrumentos para garantir a equalização entre a força, o volume dos graves e o tom da melodia. O MC é aquele que conduz as palavras em longas narrativas em sintonia com o ritmo proposto. $\mathrm{O}$ corpo e a linguagem são incorporados no movimento dos jovens nos passos da dança breaking. O graffitti é a arte visual das ruas para os passantes e pressupõe uma intervenção no espaço público por meio de cores e ideias estampadas nos muros da cidade (ARRUDA, 2017). O último e quinto elemento é o conhecimento que perpassa todos os outros pontos e se refere ao reconhecimento histórico das questões políticas e da desigualdade social que dizimaram e ainda dizimam a população negra. Estes elementos compõem um modo de pensar e propor arte como estratégia de enfrentamento às violências estrutural, subjetiva e simbólica contra os afrodescendentes.

Segundo Amaral (2013a, 2013b), as inovações tecnológicas, como a internet e as redes sociais, foram o terreno fértil para o avanço global da cultura hip-hop. Acresce-se a isso a crise financeira e as opções políticas dos governos Ronald Reagan (1980-1984) e George Bush (2001-2009), que reforçaram a lógica excludente da globalização, cujas principais consequências foram: o corte profundo nos investimentos sociais, a progressiva perda de emprego e a queda na renda da metade da população mundial nos últimos trinta anos, com consequências nefastas para as famílias e jovens em situação de vulnerabilidade social. Como exemplo, a autora cita o fato de que cada vez menos postos de trabalho são oferecidos às camadas mais jovens da população; estes, muitas 
vezes, também não tiveram acesso às instituições escolares e artísticas que poderiam ampliar o seu repertório cultural. Este modelo financeiro e político influenciou a Terra Brasilis de modo perverso. Amaral (2011) denomina de diáspora afro-indígena-brasileira uma peculiaridade da cidade de São Paulo, que foi e ainda é ponto de refúgio para muitos migrantes e imigrantes em busca de ascensão social e melhores condições de vida. Além da precarização das condições de trabalho, outro importante elemento deste cenário é a especulação imobiliária, favorecendo um movimento intenso de gentrificação, processo socioeconômico de valorização imobiliária que afasta a população mais pobre cada vez mais para as periferias urbanas, contribuindo também para o crescimento desordenado das cidades, sem nenhuma atuação mais inclusiva por parte do Estado. Há assim, segundo a autora, o surgimento de uma hiperperiferia para a qual a população pobre foi literalmente empurrada e relegada aos fundões da cidade (AMARAL, 2013b). Há que se acrescentar também a emergência e o crescimento de uma verdadeira guerra urbana entre policiais e o tráfico de drogas, na qual todos os moradores das periferias acabam sendo afetados. Grande parte dessa população é composta por migrantes tidos como desenraizados, dado que é possível observar um progressivo apagamento das raízes históricas e da memória sobre as suas origens e sua cultura, sendo todos bombardeados pelos modos hegemônicos de vida veiculados e impostos pela Indústria Cultural. Ao mesmo tempo, nestes espaços vemos surgir a produção de múltiplos modos de resistência política e cultural, de modo que os sujeitos se deparam com oportunidades de resgatar e construir novas subjetividades por meio da "luta por moradia, educação, condições sanitárias decentes, enfim, pelo direito a uma vida digna" (AMARAL, 2013b, p. 146).

É neste campo de lutas que Amaral (2013b) afirma a importância da cultura hip-hop na formação dos jovens periféricos brasileiros, entendida como estratégia para mantê-los vivos e criativos na busca por novas formas de se posicionar no mundo. Há um apelo universal desta cultura, relacionado ao seu hibridismo, dado que inventa uma forma de comunicação entre culturas distintas por meio da criação de músicas de resistência e de protesto que clamam por liberdade e pela garantia dos direitos dos jovens. Uma especificidade do rap no Brasil é a menção aos quilombos, que atualiza o:

[...] desejo de liberdade e de reconhecimento que hoje se traduz pelo caráter crítico-destrutivo de suas letras e de afirmação étnico-social, denunciando a desigualdade e exigindo tudo aquilo que vem sendo negado ao povo brasileiro, particularmente aos afrodescendentes (AMARAL, 2013b, p. 154).

Cerruti (2014) faz uma crítica a certos discursos capitalísticos que associam de modo automático juventude periférica e violência, sugerindo que para desconstruir esta forma de olhar para a cultura da periferia há que se lutar por novas formas de enunciação, visando auferir a estes jovens a "dignidade de criação", de forma a "destacar modos de legitimação subjetiva e política". É assim que a psicanalista destaca a posição ética e política do grupo Racionais MC's, que conseguiu projeção nacional com letras que desconstroem o mito imaginário em torno do homem cordial brasileiro e da ausência de racismo na sociedade. Assim, o grupo tem sido original na forma de falar sobre a violência nas periferias brasileiras " $[\ldots]$ aliando a força poética e a histórica, fazendo tremer os pilares do discurso tradicional que difunde uma imagem intimamente atrelada aos valores da miscigenação e da conciliação de classe" (CERRUTI, 2016, p. 129).

Kehl (1999) também ressalta a importância do ritmo e da poesia, presentes nas letras das músicas produzidas pelo Racionais MC's, principalmente naquilo que elas apresentam de uma nova rede discursiva na construção de relações horizontais entre os grupos, indo na contracorrente das imposições relacionais hierarquizadas da sociedade capitalista. A ensaísta afirma que na letra da música "Júri Racional", do rapper Mano Brown, talvez haja um convite para:

[...] uma "atitude" que sustente o amor-próprio entre os negros contra o sentimento de inferioridade produzido pela discriminação, o que passa pela afirmação da raça - este significante tão duvidoso, que produz discriminação ao mesmo tempo em que indica a diferença (KEHL, 1999, p. 102).

O texto de Kehl foi publicado na década de 90e parece refletir um momento histórico da produção cultural brasileira que denunciava a vinculação perversa entre preconceito racial e desigualdade social.

Já se passaram mais de 20 anos, do fim da década de 90 até hoje, embora nada tenha ocorrido para alterar significativamente esta situação perversa e genocida contra jovens, negros e periféricos. Porém, a resistência persiste, e muitas produções artísticas, culturais e acadêmicas estão buscando criar estratégias para conter a peculiaridade desta crueldade "à brasileira", direcionada a uma população específica. A roda de conversa que aconteceu dentro do espaço universitário se situa nesta corrente cultural de resistência, dado que visou fazer circular a palavra sobre o nosso racismo estrutural e sobre as múltiplas violências advindas dele.

\section{A roda de conversa "Hip-hop e o enfrentamento à violência"}

A roda de conversa aconteceu no dia 7 de dezembro de 2017, na Unifesp - Baixada Santista, sendo coordenada pelo professor Daniel Péricles Arruda, cujo trabalho se inscreve na perspectiva da arte como superação da invisibilidade social da juventude periférica. Ela surgiu como uma possibilidade de exercício criativo e se configurou como um evento aberto, antecipadamente divulgado, e como um convite de diálogo à academia e à comunidade.

A roda contou com a presença da equipe de articulação do Projeto de Extensão "Escuta Clínico-Política de Sujeitos em Situações Sociais Críticas", estudantes (graduação e pós-graduação) e professores da Universidade, pessoas da cultura hip-hop de diferentes lugares, além de um usuário de um serviço de saúde mental do município (Centro de Atenção Psicossocial Álcool e outras Drogas - CAPS AD). 
As pessoas, na roda e em roda, arranjaram-se para a escuta, com falas e trocas que combinavam diálogos e afetos ali presentes. Após a apresentação de todos os participantes, houve a exposição da construção sócio-histórica da cultura hip-hop. Uma questão relevante assinalada foi a de que esta cultura fora encarada com reserva por parte da sociedade, tomada inicialmente apenas como uma forma de manifestação da violência. Esta resistência se deu, primeiramente, devido ao fato de que a cultura hip-hop se contrapõe às ordens discursivas e estéticas hegemônicas, representando, portanto, uma ameaça às mesmas.

Portanto, sensibilidades ativas no encontro se expressaram em vozes ali presentes, emergindo três temas principais: a) a cultura hip-hop como um sonho possível de exercício profissional; b) a expressão cultural como ponto de ancoragem (BROIDE, J.; BROIDE, E., 2015) para os sujeitos nela envolvidos; e c) a arte produzida na periferia como modo de ocupação dos espaços públicos em distintos contextos. Apresentamos aqui cada um dos temas e como a discussão repercutiu nos participantes de modo a articular experiências e produção de conhecimento.

\section{A arte como profissão e o despertar para um sonho possível}

O ponto disparador da roda de conversa foi a apresentação da experiência do professor universitário Daniel Péricles Arruda como coordenador de oficinas de rap, oferecidas para adolescentes em cumprimento de medida socioeducativa de internação em Belo Horizonte (MG), que culminou na sua dissertação de mestrado (ARRUDA, 2012). Ele apresentou alguns resultados da sua pesquisa.

O hip-hop carrega em seu cerne a potencialidade de desconstruir narrativas hegemônicas que enredam estes jovens nas artimanhas das relações de dominação e poder. Por meio do desenvolvimento de narrativas próprias sobre si mesmos e as condições sociais que violam seus direitos, os jovens podem alcançar certa distância e pontos de escape de alguns discursos da saúde e do campo jurídico, que com frequência lhes reservam apenas os lugares de intratáveis, perigosos e irrecuperáveis (ROSA; VICENTIN, 2010). É possível ressaltar também que em algumas letras de rap há outra interpelação que a arte faz para o sujeito privado de liberdade, pois se eles recorreram a atos violentos e ilegais como única resposta desesperadora à violação cotidiana dos seus direitos sociais, o ritmo e a poesia surgem como alternativa possível para transpor uma ideia da cabeça para o papel, de modo a denunciar as situações sociais críticas que produzem sofrimentos sociopolíticos. Há a chance de aumentar o repertório cultural destes adolescentes e uma boa oportunidade para que exercitem o pensamento político, sensível e imagético.

Agora, no lugar de armas na mão, nas oficinas os jovens tinham outros recursos valiosos de enfrentamento no campo social: lápis e papel para criarem seus ritmos e poesias. A despeito de algumas dificuldades dos adolescentes com a língua portuguesa, o que sobressaiu foi o movimento de suspensão de um cotidiano institucionalizado e hierarquizado, por meio do convite à poesia e à música, subsidiando formas imaginativas de resistência e potencializando a manutenção da vida desses jovens, bem como criando laços de pertencimento simbólicos com uma cultura autônoma produzida pela periferia.

O exercício da imaginação possibilita, desse modo, a criação de projetos de vida que se descolam do destino social de classe destes jovens e apontam para a ideia da arte como profissão, ampliando o campo imaginário dos mundos possíveis em relação aos destinos outrora tidos como imutáveis. Restaurar a capacidade de sonhar com projetos de vida, aparentemente fora do alcance destes jovens, parece ser um importante modo de transpor fronteiras e imaginar um mundo mais justo que está por vir.

\section{A arte como ponto de ancoragem para o sujeito}

A arte emerge também como um importante ponto de ancoragem para o sujeito quando se articula com o cotidiano, mediando a aproximação entre as pessoas, com a abertura para a historicização e a simbolização; ela requer a criação de estratégias de enfrentamento das violações de direitos a partir da negociação e da criatividade.

Ao valorizar a livre expressão das subjetividades, o hip-hop oferece espaço às narrativas de vidas inscritas em campos onde a violência transita. Desse modo, ela pode possibilitar a mudança de rotas de vidas e de novos movimentos e posicionamentos subjetivos e políticos diante do mundo. Os discursos que circulam na cultura hip-hop indicam modos de reconhecimento mútuo e pertencimento dos jovens, atribuindo novos valores e posições no laço social. Ou seja, este modo de circulação da palavra pode romper com a lógica de humilhação social sustentada por um discurso provindo de um modelo de produção de exclusão socioeconômica.

Nessas camadas interligadas, a arte, que tem como uma das formas de expressão a cultura hip-hop, se manifesta como dispositivo potente de cuidado e possibilidade de ancoragem dos sujeitos em situações sociais críticas. Ela se apresenta como estratégia de enfrentamento às desigualdades sociais e fortalecimento dos laços sociais, contribuindo para manter os jovens vivos e criativos. A arte permite que os sujeitos criem e compartilhem seus próprios olhares sobre si e sobre o mundo, não se limitando exclusivamente à subsunção ao olhar externo e, em grande parte dos casos, discriminatório - seja ele o jurídico, o midiático, o psiquiátrico ou o econômico.

No compartilhamento de suas experiências no laço social, em que a violência se inscreve como estratégia de poder e dominação, criam-se condições de acesso ao campo simbólico, em elementos que favorecem a resistência coletiva à manipulação da vida e da morte no campo social. Nessa direção, o hip-hop produz e veicula um olhar próprio e um conhecimento sobre as raízes das desigualdades sociais, reconhecendo a face sociopolítica de seus sofrimentos e reposicionando-as em relação aos seus discursos, lutos e lutas, não apenas como vítimas ou algozes, mas como testemunhas de um tempo e de um espaço social (ROSA, 2016). 


\section{A arte e a ocupação de espaços públicos}

Este tema repercutiu como possibilidade de desmistificar os diferentes modos de compreender e de ocupar o espaço público em suas interfaces com as manifestações artísticas. Se os jovens das classes sociais mais abastadas economicamente, cada vez mais, se afastam dos espaços públicos como modo de responder ao discurso sobre a segurança e ao suposto perigo de uma sociedade violenta, a eles é disponibilizado o acesso a outros espaços de convivência e aos bens imateriais e materiais produzidos pela humanidade, o que aumenta o seu repertório cultural e os suportes sociais, institucionais e familiares diante das agruras da vida. Este distanciamento também contribui para o processo de desvalorização social crescente dos espaços públicos, entendidos cada vez mais como perniciosos, e até mesmo desnecessários, para a constituição dos laços sociais e funcionamento da sociedade. Nesta perspectiva, para os jovens que vivem cotidianamente sob a iminência da violência e da morte, configuradas em vidas marcadas pelas situações sociais críticas, o espaço público se vê progressivamente reduzido a um "cenário rua”, cada vez mais desinvestido pelo Poder Público - ou investido apenas de dispositivos repressivos. Tal cenário, desinvestido e desvalorizado, pode acabar se configurando com uma das diversas formas de violência em que as vidas permanecem marcadas e desamparadas. Sendo assim, quais estratégias para driblar a morte e permanecer vivo este jovem utiliza no seu habitual cenário permeado de violência? Ante este panorama mortífero, como e com o que ele se agarra à vida?

As respostas a estas questões por algumas pessoas durante a roda foram remetidas às condições do nascedouro da cultura hip-hop e seus cinco elementos: é a rua e são os espaços públicos que despontam como importantes cenários e palcos nos quais a dança, a voz, a musicalidade e o grafite são exercitados. São, portanto, nestes espaços da cidade que irrompem as potências criativas de movimento e militância, permitindo novos significados e a invenção de múltiplos modos de ocupação da urbe.

\section{Considerações finais}

As discussões e debates sobre as relações étnico-raciais no Brasil já datam de algumas décadas, em tentativas recorrentes de contribuir para mudar o cenário social, que esbarra em avanços e retrocessos e aponta para a complexidade do tema e para a necessidade de reflexões persistentes e diferenciadas nos mais diversos contextos. Poucos passos importantes em tal direção foram dados, e ainda carecemos de espaços de diálogo e reflexão sobre o racismo brasileiro, especialmente se considerarmos sua articulação entre produção de conhecimentos e comunidade, universidade e sociedade.

Espera-se que a psicologia, assim como as demais ciências humanas e sociais, contribua com fundamentações teóricas para a compreensão do racismo institucional e estrutural, mas, além disso, com a criação de modos de atenção e enfrentamento ao sofrimento sociopolítico de- sencadeado pela segregação social - responsabilidade presente nas intervenções psicanalíticas em prol da transformação social.

$\mathrm{Na}$ roda de conversa, as manifestações artísticas da cultura hip-hop mediaram a reflexão e compartilhamento de vivências atravessadas pela violência e pelo racismo. Nesse contexto, o hip-hop foi entendido enquanto uma produção cultural que permite o reconhecimento da voz dos jovens e, para além disso, valoriza a potência de suas experiências e afirma sua criatividade e lugar no mundo.

Para finalizar, convidamos psicólogos e profissionais de diferentes áreas para que também criem estratégias de enfrentamento ao racismo e às diversas formas de violência que abatem a sociedade brasileira, dentro e fora do ambiente universitário.

\section{Informações sobre os autores:}

\section{Jaquelina Maria Imbrizi \\ (iD) https://orcid.org/0000-0003-0950-6174 \\ (9) http://lattes.cnpq.br/8682215618761531}

Possui graduação em Psicologia pela Universidade Estadual Paulista Júlio de Mesquita Filho (1984 -1988), mestrado e Doutorado em Educação: História, Política, Sociedade pela Pontifícia Universidade Católica de São Paulo (1997) e (2001) e pós-doutorado pelo Programa de Estudos Pós-Graduados em Psicologia: Psicologia Social da Pontifícia Universidade Católica de São Paulo, Núcleo de Estudos e Pesquisa em Psicanálise e Política (2013 - 2015). Professora Associada da Universidade Federal de São Paulo - Campus Baixada Santista onde desenvolve atividades na graduação e nos Programas de Pós-graduação Stricto Sensu Ensino em Ciências da Saúde (Modalidade Profissional) e Interdisciplinar em Ciências da Saúde (Mestrado e doutorado acadêmicos). Membro do Laboratório de Psicanálise, Sociedade e Política (USP) e do Laboratório de Psicanálise da Unifesp - Campus Baixada Santista - Linha de Pesquisa: Núcleo de Estudos, Pesquisa e Extensão: Psicanálise, Arte e Sociedade (PAS). Tem experiência na área de Psicologia, com ênfase em Psicanálise e Psicologia Social, atuando principalmente nos seguintes temas: arte, cultura e sociedade; mal-estar e violência; narrativa de história de vida e grupo como dispositivo.

\section{Eduardo de Carvalho Martins}

\section{(iD) https://orcid.org/0000-0001-6702-1680}

\section{(9) http://lattes.cnpq.br/4618092653487544}

Professor-pesquisador da Universidade Federal de São Carlos no curso de Pós Graduação em Coordenação Pedagógica. Psicólogo do curso de Psicologia da Universidade Federal de São Paulo Campus Baixada Santista. Doutor em Epistemologia da Psicanálise pela Universidade Federal de São Carlos (2012). Especialista em Gestão Pública pela Universidade Federal do Tocantins (2012), Especialista em Psicologia Clínica pela Faculdade Jaguariúna (2014). Mestre em Ética pela Universidade Federal de São Carlos (2006). Possui graduação em Psicologia pela UFSCar (2002). Atua com os seguintes temas: Educação, Educação Popular, Educação Ambiental, Clínica ampliada, Psicanálise, Ética, Epistemologia, Direitos Humanos e Economia Solidária.

\section{Marcela Garrido Reghin}

(iD) https://orcid.org/0000-0002-6883-3207

\section{(9) http://lattes.cnpq.br/2936556041491104}

Graduada em Psicologia pela Universidade Federal do Triângulo Mineiro - UFTM. Mestre em Ciências pelo Programa de Pósgraduação Interdisciplinar em Ciências da Saúde da Universidade Federal de São Paulo, campus Baixada Santista - UNIFESP - BS. Especialista em Saúde Mental / Atenção Psicossocial na modalidade Residência Multiprofissional em Saúde no Programa 
Rede de Atenção Psicossocial pela Universidade Federal de São Paulo, campus Baixada Santista - UNIFESP - BS, em parceria com a Secretaria Municipal de Santos/SP. Membro do grupo de pesquisa Laboratório Interdisciplinar Ciências Humanas, Sociais e Saúde LICHSS (Diretório de Grupos de Pesquisa - CNPq). Atuação em práticas clínicas, institucionais e de pesquisa na área de Saúde Mental, Saúde Mental na infância, Saúde Coletiva, com ênfase na interdisciplinaridade e produção de cuidado em rede.

Danielle Kepe de Souza Pinto

(iD) https://orcid.org/0000-0002-8998-6069

(9) http://lattes.cnpq.br/8486799083463049

Psicóloga formada pela Universidade Católica de Santos (2009), Especialista em Terapia de Casais e Famílias na abordagem Sistêmica Breve pela Faculdade Brasil (2015) e Mestre em Ensino e Ciências da Saúde pela Universidade Federal de São Paulo. Com experiência na área clínica e institucional com enfoque em Psicologia Social. Experiência em trabalhos com violência, violação de direitos, crianças e adolescentes, famílias e Assistência Social. Membro da Associação Brasileira de Psicologia Social (ABRAPSO) - Baixada Santista.

Daniel Péricles Arruda

(iD) https://orcid.org/0000-0002-8347-8215

(9) http://lattes.cnpq.br/2377455944784166

Pós-doutor em Psicologia Social pela Pontifícia Universidade Católica de São Paulo (PUC-SP); formando em Psicanálise pelo Instituto Langage; doutor em Serviço Social pela PUC-SP; mestre em Serviço Social pela mesma instituição como bolsista do Ford Foundation International Fellowships Program (Turma 20102012); graduado em Serviço Social pela Pontifícia Universidade Católica de Minas Gerais. Atualmente, é professor adjunto A I no curso de graduação em Serviço Social da Universidade Federal de São Paulo e membro do conselho editorial das revistas International Journal for Quality in Health Care (IJQHC) e Journal of Quality in Health Care \& Economics (JQHE). Autor dos livros Constelação de Ideias (2011), Poéticas de um Estudante (2016), Quanto menos Informados, mais Dominados (2017) e Espelho dos Invisíveis: A Arte no Trabalho com Adolescentes em Cumprimento de Medida Socioeducativa (2018). Supervisor institucional. Tem experiência com medidas socioeducativas; acolhimento institucional; atendimento à criança e ao adolescente em situação de violências e sistema prisional, com ênfase na estruturação e sistematização de serviços; no trabalho social com famílias; na questão étnico-racial; e na arte como mediação da prática profissional. Em sua trajetória juvenil, possui também experiência como coletor de materiais recicláveis; ajudante de pedreiro; pintor; datilógrafo; jogador de futebol; promotor de vendas; vendedor; e educador. É poeta e rapper conhecido como Vulgo Elemento. Portanto, este currículo é constituído por duas dimensões do conhecimento que se articulam: a arte e a ciência. www.vulgoelemento.com.br

\section{Contribuições dos autores}

Todos os autores participaram da concepção, análise de resultados e contribuíram efetivamente na realização do artigo.

\section{Como citar este artigo:}

\section{ABNT}

IMBRIZI, Jaquelina Maria et al. Cultura hip-hop e enfrentamento à violência: uma estratégia universitária extensionista. Fractal: Revista de Psicologia - Dossiê Psicologia e epistemologias contrahegemônicas, Niterói, v. 31, n. esp., p. 166-172, set. 2019. https:/ doi.org/10.22409/1984-0292/v31i_esp/29041

\section{APA}

Imbrizi, J. M., Martins, E. C., Reghin, M. G., Pinto, D. K. S, \& Arruda, D. P. (2019, set.). Cultura hip-hop e enfrentamento à violência: uma estratégia universitária extensionista. Fractal: Revista de Psicologia - Dossiê Psicologia e epistemologias contrahegemônicas, 31(esp.), 166-172. doi: https://doi.org/10.22409/19840292/v31i_esp/29041

\section{Referências}

AMARAL, Monica Guimaraes Teixeira do. O rap, o hip-hop e o funk: a "eróptica" da arte juvenil invade a cena das escolas públicas nas metrópoles brasileiras. Psicologia USP, São Paulo, v. 22, n. 3, p. 593-620, 2011. http://dx.doi.org/10.1590/ S0103-65642011005000025

AMARAL, Monica Guimaraes Teixeira do. Expressões estéticas contemporâneas de resistência da juventude urbana e a luta por reconhecimento: uma leitura a partir de Nietzsche e Axel Honneth. Revista do Instituto de Estudos Brasileiros, São Paulo, n. 56, p. 73-100, 2013a. http://dx.doi.org/10.11606/ issn.2316-901X.v0i56p73-100

AMARAL, Monica Guimaraes Teixeira do. O Rap, a revolução e a educação: do Bronx à Primavera Árabe. Ide, São Paulo, v. 36, n. 56, p. 145-159, 2013b. Disponível em: http://pepsic. bvsalud.org/scielo.php?script=sci arttext\&pid=S0101$31062013000200010 \& \operatorname{lng}=p t \& n r m=i$ so. Acesso em: 26 jun. 2017.

ARRUDA, Daniel Péricles. Espelho dos invisiveis: o RAP e a poesia no trabalho prático-reflexivo com adolescentes em cumprimento de medida socioeducativa de internação em Belo Horizonte (MG). 2012. Dissertação (Mestrado em Serviço Social). Programa de pós-graduação da Pontifícia Universidade Católica de São Paulo, São Paulo, 2012.

ARRUDA, Daniel Péricles. Cultura hip-hop e serviço social: a arte como superação da invisibilidade social da juventude periférica. 2017. Tese (Doutorado em Serviço Social)-Faculdade Serviço Social, Pontifícia Universidade Católica de São Paulo, São Paulo, 2017.

BRASIL. Presidência da República. Casa Civil. Subchefia para Assuntos Jurídicos. Lei $n^{\circ} 12.711$, de 29 de agosto de 2012. Dispõe sobre o ingresso nas universidades federais e nas instituições federais de ensino técnico de nível médio e dá outras providências. 2012. Disponível em: http://www.planalto. gov.br/ccivil 03/ ato2011-2014/2012/lei/112711.htm. Acesso em: 12 jul. 2018.

BROIDE, Jorge; BROIDE, Emília Estivalet. A psicanálise em situações sociais críticas. São Paulo: Escuta, 2015.

CERQUEIRA, Daniel et al. Atlas da violência 2017. São Paulo: Instituto de Pesquisas Econômicas Aplicadas, 2017.

CERRUTI, Marta Quaglia. Movimento hip-hop: novas perspectivas para o processo de responsabilização do jovem em conflito com a lei. Revista Brasileira de Ciências Criminais, $\mathrm{n}$. 109, p. 313-324, 2014.

CERRUTI, Marta Quaglia. O jovem e o rap: ética e transmissão nas margens da cidade. 2016. Tese (Doutorado em Psicologia) Instituto de Psicologia, Universidade de São Paulo, São Paulo, 2016

CRUZ, Elaine Patrícia. Crimes de Maio causaram 564 mortes em 2006: entenda o caso. Agência Brasil, 2016. Disponível em: $\quad$ http://agenciabrasil.ebc.com.br/direitos-humanos/ noticia/2016-05/crimes-de-maio-causaram-564-mortes-em2006-entenda-o-caso. Acesso em: 7 abr. 2018.

KEHL, Maria Rita. Radicais, Raciais, Racionais: a grande fratria do rap na periferia de São Paulo. São Paulo em perspectiva, São Paulo, v. 13, n. 3, p. 95-106, jul./set. 1999. http://dx.doi. org/10.1590/S0102-88391999000300013 
IMBRIZI, Jaquelina Maria; MARTINS, Eduardo de Carvalho. Escuta clínico-política de sujeitos em situações sociais críticas. Projeto de Extensão Universitária-Unifesp - Baixada Santista, Santos, SP, Brasil, 2017.

MACHADO, Thaís Fabiana Farias. Territórios, sociabilidades e jovens da Zona Noroeste de Santos - SP: significados e experiências em contextos de violência urbana. 2017. Dissertação (Mestrado Interdisciplinar)-Universidade Federal de São Paulo, Baixada Santista, Santos, 2017.

RODRIGUES, Mateus. Após cotas, universidades federais ficam 'mais populares e negras'. G1, 2016. Disponível em: $\quad$ https://g1.globo.com/educacao/noticia/apos-cotasuniversidades-federais-ficam-mais-populares-e-negras-dizestudo.ghtml. Acesso em: 7 de abr. 2018.

ROSA, Miriam Debieux. A clínica psicanalítica em face da dimensão sociopolítica do sofrimento. São Paulo: Escuta/ Fapesp, 2016.

ROSA, Miriam Debieux; VICENTIN, Maria Cristina. Os intratáveis: o exílio do adolescente do laço social pelas noções de periculosidade e irrecuperabilidade. Revista Psicologia Política, São Paulo, v. 10, n. 19, p. 107-124, 2010. Disponível em: $\quad$ http://pepsic.bvsalud.org/scielo.php?script=sci arttext\&pid=S1519-549X2010000100010\&lng=pt\&nrm=iso. Acesso em: 12 maio 2018.

WAISELFSZ, Julio Jacobo. Mapa da violência 2016: homicídios por arma de fogo no Brasil. Rio de Janeiro: FLACSO Brasil, 2016. 